\title{
Past, present, and future of molecular and cellular oncology
}

\author{
Lorenzo Galluzzi ${ }^{1,2,3}$, Ilio Vitale ${ }^{1,2,3}$ and Guido Kroemer 1,4,5,6,7* \\ 1 INSERM, U848, Villejuit, France \\ 2 Institut Gustave Roussy, Villejuif, France \\ ${ }^{3}$ Université Paris-Sud, Villejuif, France \\ ${ }^{4}$ Metabolomics Platform, Institut Gustave Roussy, Villejuif, France \\ ${ }^{5}$ Centre de Recherche des Cordoliers, Paris, France \\ ${ }_{6}^{6}$ Pôle de Biologie, Hôpital Européen Georges Pompidou, Assistance Publique-Hôpitaux de Paris, Paris, France \\ 7 Université Paris Descartes, Paris, France
}

Edited by:

Frank Madeo,

Karl-Franzens-Universität, Austria

\section{Reviewed by:}

Kai-Uwe Fröhlich,

University of Graz, Austria

Valter Longo,

University of Southern California

Los Angeles, USA

*Correspondence

Guido Kroemer, PU-PH, INSERM,

U848, Institut Gustave Roussy, Pavillon de Recherche 1, 39 rue Camille

Desmoulins, F-94805 Villejuif, France. e-mail:kroemer@orange.fr
In the last 20 years, the field of cellular and molecular oncology has been born and has moved its first steps, with an increasingly rapid pace. Hundreds of oncogenic and oncosuppressive signaling cascades have been characterized, facilitating the development of an ever more refined and variegated arsenal of diagnostic and therapeutic weapons. Furthermore, several cancer-specific features and processes have been identified that constitute promising therapeutic targets. For instance, it has been demonstrated that microRNAs can play a critical role in oncogenesis and tumor suppression. Moreover, it turned out that tumor cells frequently exhibit an extensive metabolic rewiring, can behave in a stem cell-like fashion (and hence sustain tumor growth), often constitutively activate stress response pathways that allow them to survive, can react to therapy by engaging in non-apoptotic cell death programs, and sometimes die while eliciting a tumor-specific immune response. In this Perspective article, we discuss the main issues generated by these discoveries that will be in the limelight of molecular and cellular oncology research for the next, hopefully few years.

Keywords: immunogenic cell death, necroptosis, non-oncogene addiction, regulated necrosis, oncometabolites
During the last decade, tremendous advances have been made toward an increasingly more precise understanding of cancer at both the cellular and molecular levels. It has been shown that in specific cellular settings, microRNAs (miRNAs) can exert bona fide oncogenic or oncosuppressive functions (Croce, 2009) and that tumor cells often, if not always, exhibit an extensive metabolic reprogramming (Kroemer and Pouyssegur, 2008); cancer stem cells (CSC) have been extensively studied (Visvader and Lindeman, 2008); the importance of oncogene/non-oncogene addiction (Luo et al., 2009), and of immunogenic cancer cell death (Zitvogel et al., 2010) has been established; and novel programmed cell death (PCD) modalities have been characterized (Vandenabeele et al., 2010), just to mention a few examples (Figure 1). This knowledge is rapidly being translated into ever more reliable diagnostic and prognostic biomarkers as well as into a broad array of new therapeutic tools. Moreover, the great promises that personalized anticancer strategies held at the end of the 1990s have turned into a clinically exploitable reality. Still, there remain multiple unresolved issues. For instance, how can we exploit the biology of CSC to render them sensitive to therapy? How can we trigger the immunogenic death of tumor cells and circumvent resistance? How can the tumor-stroma interaction be targeted for developing scarcely toxic yet highly efficient anticancer strategies? These are only some of the questions that will drive the work of cellular and molecular oncologists for the next few years. We must concentrate our efforts to answer these great challenges, as the underlying fundamental knowledge will undoubtedly sustain the development of revolutionary clinical applications.

\section{miRNA AND CANCER}

In 2002, the laboratory lead by Croce (2009) found that two nonprotein-coding RNA (actually miRNA) genes, $m i R-15 a$ and $m i R$ 16-1, map to a region of chromosome 13 (13q14) that is frequently deleted in chronic lymphocytic leukemia (CLL) and that miR-15a and $m i R-16-1$ are indeed lost in approximately $70 \%$ of CLL cases (Calin et al., 2002). This seminal work has paved the way to the elucidation of the multifaceted role of miRNAs in cancer. Later, it has been shown that miRNAs like $m i R-15 a$ and $m i R-16-1$ exert oncosuppressive functions by negatively regulating the expression of oncogenes such as the anti-apoptotic protein BCL2 (Cimmino et al., 2005). Similarly, members of the let-7family of miRNAs, whose expression is lost in lung and breast cancer as well as in other solid and hematological malignancies, act as tumor suppressors by inhibiting the expression of RAS (Johnson et al., 2005). Of note, there are also miRNAs that promote oncogenesis by targeting oncosuppressors. For instance, members of the $m i R-17-92$ cluster as well as $m i R-21$, which are upregulated in multiple hematopoietic and solid tumors, inhibit phosphatase and tensin homolog (PTEN; Meng et al., 2007; Mendell, 2008).

In most cases, the deregulation of miRNAs derives from genetic defects (e.g., deletions, point mutations) in miRNA genes, in turn resulting in aberrant expression levels. However, there are additional mechanisms that provoke miRNA deregulation and by which miRNA can contribute to cancer. For instance, the miR-17-92 cluster is transactivated by MYC, an oncoprotein that is often overexpressed in cancer (O'Donnell et al., 2005). In this context, $m i R-17-92$ functions as an oncogenic effector of MYC. The expression of miRNAs 


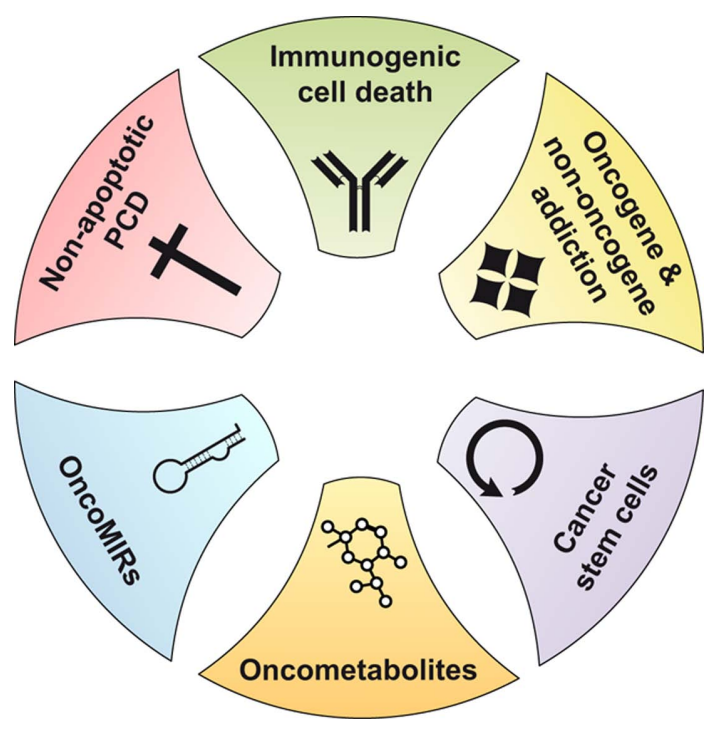

FIGURE 1 |The great discoveries of the last decade of molecular and cellular oncology research. MIRs, microRNAs; PCD, programmed cell death.

can also be compromised by epigenetic events, such as promoter hypermethylation at $\mathrm{CpG}$ islands. This is the case of $m i R-127$, an oncosuppressive miRNA that inhibits the oncogene BCL6 and that is frequently silenced in bladder tumors owing to promoter hypermethylation (Saito et al., 2006). Intriguingly, some miRNAs such as $m i R-29, m i R-148 a$, and $m i R-148 b$ have recently been shown to modulate promoter methylation by targeting DNA methyltransferases (DNMTs; Croce, 2009; Garzon et al., 2009).

Thus, important insights into the role of miRNAs in cancer pathogenesis have been provided during the past 10 years. This caused a major leap forward in molecular and cellular oncology, leading to the development of promising clinically oriented applications. For instance, Kota et al. (2009) have recently demonstrated that MYCdriven hepatocellular carcinomas (HCCs) regress in vivo upon the delivery of $m i R-26 a$, an miRNA that is normally expressed at high levels in diverse tissues but downregulated in HCC cells. In addition, efforts have been spent toward the understanding of the prognostic and predictive values of miRNA signatures in cancer (Ryan et al.,2010).

In this specific area of molecular and cellular oncology, there are at least two great challenges for the upcoming years, besides the identification of novel cancer-relevant miRNAs and their mode of action. First, based on large clinical studies, it will be important to validate the prognostic or predictive value of single miRNAs or of miRNA signatures, as this will ameliorate the understanding of disease progression and allow for patient stratification and personalized therapy. Second, it will be critical to understand how miRNAs and anti-miRNAs, which currently hold great promises as highly specific and hence relatively safe therapeutic agents, should be targeted to tumor cells in vivo.

\section{CANCER-SPECIFIC METABOLIC ALTERATIONS}

In the 1920s, the Nobel Prize winner Otto Warburg discovered that a large proportion of cancer cells display a specific metabolic alteration, i.e., they maintain high rates of glycolysis even in the presence of a normoxic environment (aerobic glycolysis). Though this phenomenon, also known as Warburg effect, is not universally applicable to all cancers, it is sufficiently prevalent for being clinically exploited to image cancer by $2-\left({ }^{18} \mathrm{~F}\right)$-fluoro-2-deoxy-Dglucose (FDG) based positron emission tomography (FDG-PET; Kroemer and Pouyssegur, 2008). Since then, several other metabolic alterations have been identified in cancer cells. Nevertheless, until recently, the Warburg effect and other cancer-specific metabolic defects have been viewed as a mere epiphenomenon of and not as an active contributor to tumorigenesis.

This has gradually changed in the past decade, driven by the milestone discovery that germline mutations in two enzymes of the Krebs cycle, namely fumarate hydratase (FH) and succinate dehydrogenase $(\mathrm{SDH})$, are associated with an increased risk of tumorigenesis (Gottlieb and Tomlinson, 2005). Initially, the reason why FH and several genes coding for $\mathrm{SDH}$ subunits (i.e., $\mathrm{SDHB}, \mathrm{SDHC}$, and $S D H D$ ) behave as classical oncosuppressive genes was obscure. Then, Selak et al. (2005) and Pollard et al. (2005) independently demonstrated that succinate and fumarate, accumulating in conditions of $\mathrm{SDH}$ and FH deficiency, respectively, inhibit prolyl hydroxylases in the cytosol leading to stabilization and activation of the oncoprotein HIF1 $\alpha$ (Pollard et al., 2005; Selak et al., 2005). These works founded the concept of "oncometabolites," i.e., metabolites that are able to drive tumorigenesis, and paved the way to the study of metabolic alterations as etiological determinants in cancer. The importance of this discovery is further corroborated by the long list of metabolic alterations that are being investigated as potential target for anticancer therapies (Kroemer and Pouyssegur, 2008). Thus, during the last decade, promising results have been obtained not only by targeting glycolysis (Bonnet et al., 2007; Simons et al., 2007) and the HIF1 signaling pathway (Brizel and Esclamado, 2006; MacKenzie et al., 2007) but also by modulating fatty acid synthesis, which is often exacerbated in cancer cells, reflecting their intense need for building blocks to sustain proliferation (Hatzivassiliou et al., 2005; Beckers et al., 2007), and other metabolic circuitries (Pouyssegur et al., 2006).

Additional metabolic alterations that selectively characterize cancer cells will surely be elucidated in the forthcoming years, hopefully leading to the development of new, potent anticancer compounds. In this context, it will be most interesting to see metabolomic research applied to molecular oncology and in particular to understand whether malignant cells are characterized by metabolomic profiles that vary during tumor progression and hence can be used for a more precise tumor grading. Of note, cancer-associated metabolic reprogramming and the underlying molecular modifications are intimately linked to all other hallmarks of tumor cells (as defined by Hanahan and Weinberg, 2000) including their limitless proliferative potential, self-sufficiency in growth signals, as well as their capacity to evade apoptosis, sustain angiogenesis, invade nearby tissues, and generate distant metastases (Kroemer and Pouyssegur, 2008). The great challenge in this respect is to identify clinically useful compounds that "double-hit" cancer cells, i.e., agents that rectify the metabolic alterations of cancer cells while simultaneously inhibiting one (or more) of their malignant features.

\section{CANCER STEM CELLS}

It is well known that tumors exhibit a high degree of internal heterogeneity, with cells displaying distinct proliferative, differentiative, and functional capacities (Heppner and Miller, 1983). At least two theories have been proposed to account for tumor heterogeneity, 
the clonal evolution (Nowell, 1976), and the CSC (Reya et al., 2001) models. The former postulates that a mutant population of cancer cells acquires a proliferative advantage and drives tumorigenesis (Nowell, 1976). The latter, which has been put forward much later and for which convincing evidence has accumulated only during the last decade, proposes a hierarchical organization of cancer cells, in which a subpopulation of stem-like cells sustains tumor growth (Reya et al., 2001). These models are not mutually exclusive. Barabe et al. (2007) showed that leukemia CSCs can evolve with time from a primitive type to one containing rearranged immunoglobulin genes, implying that CSCs themselves can undergo clonal evolution. The frequency of CSCs is highly variable, ranging from less than $1 \%$ to the vast majority of cells (Hewitt, 1958). Notably, CSCs do not necessarily match cancer-initiating cells and do not necessarily derive from the transformation of normal stem cells (Visvader and Lindeman, 2008).

Although the first evidence for CSCs was obtained in murine models of acute myeloid leukemia (AML; Lapidot et al., 1994), it has now become clear that this model applies to multiple (though perhaps not all) solid tumors. One of the first demonstrations that tumor-initiating cells can be purified from solid malignancies came from the work of Al-Hajj et al. (2003) in breast cancer. In this context, it should be noted that the CSC phenotype (with regard to surface and intracellular markers) may not necessarily be uniform across tumor types or even cancers of the same histological origin. Still, the surface markers described so far by different groups for the same tumor type exhibit some overlap, which has allowed for the identification of some molecules that might be exploited (with highly variable success rates) for the purification of CSCs. These include the ATP-binding cassette family members ABCG2 and ABCG5, aldehyde dehydrogenase 1 (ALDH1), the epithelial cell adhesion molecule EpCAM (ESA, TROP1) as well as the cell surface proteins CD24, CD44, CD90, and CD133 (Visvader and Lindeman, 2008).

The existence of CSCs has far reaching clinical and therapeutic implications. Given their tumor-initiating capability, CSCs must be eradicated to ensure long-term disease-free survival to patients. However, this is complicated by multiple facets of CSC biology. First, in some instances, CSCs enter a dormant, non-proliferative state that render them more resistant to radio- and chemotherapy (Ishikawa et al., 2007). Second, CSCs often acquire active mechanisms, for instance a particularly efficient DNA damage response, to resist anticancer therapy (Bao et al., 2006a). Third, CSCs can lose their sensitivity to treatment upon clonal evolution (Visvader and Lindeman, 2008). Intriguingly, some reports suggest that there is the possibility to selectively target the CSC compartment while sparing normal stem cells. Guzman et al. (2005) demonstrated that the natural compound parthenolide induces robust apoptosis in primary human AML but not normal hematopoietic cells, with an exquisite preference for the progenitor and stem cell populations. Similarly, Morrison's laboratory found that rapamycin, an inhibitor of the central cell regulator mechanistic target of rapamycin (MTOR), selectively targets leukemia-initiating cells that arise upon PTEN deletion (via MTOR overactivation) while sparing normal hematopoietic stem cells (HSCs; Yilmaz et al., 2006; Lee et al., 2010). CD44, which is required for the function and/or survival of CSCs but not of HSCs, has also been pointed to as a putative target for CSC-targeting anticancer strategies (Jin et al., 2006). Finally, some successful attempts have been made to decrease the resistance to therapy of CSCs by triggering the differentiation program. This approach is exemplified by the work of Piccirillo et al. (2006), who could attenuate the tumor-forming capacity of $\mathrm{CD} 133^{+}$glioblastoma CSCs in vivo by inducing their differentiation into astrocytelike cells with bone morphogenic proteins (BMPs).

Although substantial evidence on the existence of CSCs has accumulated during the past 10 years, there are still a number of critical issues that remain to be addressed. This is due not only to the elusive nature of CSCs but also to technical problems with their purification. One great challenge to CSC research is therefore the development of more refined techniques for CSC isolation, which in turn will allow to answer several other hitherto unresolved questions. First, is there a CSC-specific marker (or a combination of markers) that is common to all tumors of the same histological type? Second, can this combination be exploited for selectively targeting CSC while sparing normal stem cells? Moreover, there is an increasing interest in the possibility that solid CSCs not only may be hierarchically distinct from other tumor cells but also may occupy a CSC-restricted microenvironment, in which they would engage in preferential relationships with cancer-associated stromal cells including fibroblasts, macrophages, and endothelial cells, which perhaps would contribute to CSC selfrenewing capabilities as well as to their resistance to therapy. Recent findings by Calabrese et al. (2007) and Bao et al. (2006b) demonstrate that glioma $\mathrm{CD}_{133^{+}} \mathrm{CSC}$ (but not $\mathrm{CD} 133^{-}$) cells can form highly vascular brain tumors in mice, a process that can be inhibited by bevacizumab, a vascular endothelial growth factor (VEGF)-neutralizing antibody. One of the most challenging issues for the upcoming years will be to determine whether solid CSCs do indeed occupy a restricted niche in the tumor architecture and whether there is the possibility to selectively target this niche for therapy.

\section{ONCOGENE AND NON-ONCOGENE ADDICTION}

During the past two decades, our understanding of the pathogenesis of cancer has tremendously been ameliorated, and it is now clear that tumorigenesis constitute a complex, multistep process during which cells progressively acquire a common set of features that underlie their malignancy. These characteristics include the abovementioned hallmarks of tumor cells proposed by Hanahan and Weinberg (2000) as well as traits that have more recently been identified, such as the ability of cancer cells to escape immune surveillance, an extensive metabolic rewiring (Kroemer and Pouyssegur, 2008), and alterations in the autophagic machinery (Morselli et al., 2009). Most of these features can be ascribed to genetic or epigenetic events that can bring about the gain-offunction, amplification, or overexpression of oncogenes and/or the loss-of-function, deletion, or silencing of oncosuppressor genes (Hahn and Weinberg, 2002). In addition to these major alterations, there appear to be several low-frequency changes that contribute to tumorigenesis (Greenman et al., 2007), suggesting that each cancer is characterized by a specific and complex combination of genetic and epigenetic alterations that underlie the malignant phenotype. This enormous complexity and heterogeneity constitutes an obvious problem for anticancer therapy, as it is difficult to appreciate which are the critical nodes that should be targeted to reverse malignancy (via cell death, senescence, or differentiation). This picture is further complicated by the fact that cancer cells also exhibit a number of phenotypes that are not responsible 
for initiating tumorigenesis, including DNA damage/replication, proteotoxic, mitotic, metabolic, and oxidative stress, which have collectively been referred to as "stress phenotypes" (Luo et al., 2009). Although some of these phenotypes are not restricted to malignant cells and can be observed in cancer-unrelated settings (e.g., chronic inflammation), tumor cells must activate support mechanisms in order to tolerate these conditions and oncogenic stress.

The activation of oncogenes and/or the loss of oncosuppressor genes are required not only for tumorigenesis but also for the survival of established tumors. This concept is widely known under the name of "oncogene addiction" and has elegantly been demonstrated by experiments aimed at either suppressing oncogene activity or restoring tumor suppressor function. For instance, MYC-driven papillomas, lymphomas, and osteosarcoma have been shown to regress upon MYC withdrawal in vivo (Felsher and Bishop, 1999; Pelengaris et al., 1999; Jain et al., 2002). Along similar lines, the addiction to HRAS, BCR-ABL, and KRAS has been demonstrated in murine models of melanoma, leukemia, and colorectal cancer (Shirasawa et al., 1993; Chin et al., 1999; Huettner et al., 2000). Moreover, reintroduction of TP53 has recently been shown to induce the regression of TP53-deficient tumors (Ventura et al., 2007; Xue et al., 2007). In the past decade, several oncoprotein inhibitors have been developed and entered the clinical practice including imatinib (targeting BCR-ABL), gefitinib and erlotinib (both inhibiting the epidermal growth factor receptor, EGFR), and trastuzumab (targeting HER2; Luo et al., 2009). Conversely, no drugs have been released to date that would restore oncosuppressor functions, perhaps because it is much more difficult to achieve the pharmacological reactivation of deficient genes/proteins than the inhibition of hyperactivated oncogenes.

Cancer cells are not only addicted to oncogenes. Partially owing to the high levels of stress that tumor cells must continuously endure and partially because of the extensively rewired pathways that result from the oncogenic process itself, it appears that malignant cells depend for their survival on the activity of a wide array of genes and functions that are not inherently oncogenic per se. The concept of "non-oncogene addiction" has been first formulated by Solimini et al. (2007) and has profound therapeutic implications. First, since tumors are characterized by a whole compendium of genetic alterations (among which only a few involve bona fide oncogenes and oncosuppressor genes), there is ample space for developing pharmacological agents that exert anticancer effects by reversing non-oncogene addiction. Second, there is an entire category of cell-extrinsic pathways that underlie nononcogene addiction, including vascular and stromal functions. While targeting these circuitries might prove more difficult for selectivity issues (e.g., it might be complicated to target tumor vessels while sparing normal ones), it also constitutes a rather promising approach, since normal cells that support tumors tend to be genetically more stable than cancer cells and hence less prone to evolve toward drug resistance (Solimini et al., 2007; Luo et al., 2009). Non-oncogene addiction mainly represents the dependency of cancer cells on stress support pathways. Thus, at least on theoretical grounds it would be possible to selectively kill tumor cells by either inhibiting these cytoprotective mechanisms or by exacerbating stress. Several lines of evidence obtained in preclinical models suggest that non-oncogene addiction constitutes a clinically exploitable phenomenon (Solimini et al., 2007; Luo et al., 2009). One major challenge for the forthcoming decade is to refine our knowledge of non-oncogene addition and to understand to which extent this phenomenon is conserved across distinct types of cancer. It will also be particularly interesting to see the results of clinical trials based on non-oncogene addiction inhibitors alone or in combination with classic anticancer drugs.

\section{NOVEL PATHWAYS OF PROGRAMMED CELL DEATH AND THE IMMUNOGENIC DEATH OF CANCER CELLS}

For decades, developmental and pathological PCD was believed to be executed by predominantly apoptotic mechanisms and was associated with the morphological and biochemical manifestations of apoptosis (e.g., pyknosis, karyorrhexis, blebbing, caspase activation; Galluzzi et al., 2007; Kroemer et al., 2007, 2009). Conversely, necrosis was generally regarded to as a merely accidental process (Vandenabeele et al., 2010). Along similar lines, it was firmly believed that the apoptotic death of cancer cells that respond to radio- and/or chemotherapy would be unable elicit an immune response (i.e., it would be immunologically silent) or sometimes even would actively inhibit the activation of the immune system (i.e., it would be tolerogenic), as opposed to the well known proinflammatory nature of necrotic cell death (Zitvogel et al., 2010). During the past few years, it has become clear that both these preconceived ideas represent gross oversimplifications.

Thus, several lines of evidence have been collected demonstrating that: (i) necrosis can be a precisely regulated process, both in its occurrence and in its course, (ii) developmental PCD can be mediated by the molecular machinery for necrosis, and that (iii) PCD can manifest with morphological traits of necrosis, including organelle swelling, dilatation of the nuclear membrane, chromatin condensation into small, irregular, circumscribed patches, and increased cell volume (oncosis), culminating in the rupture of the plasma membrane (Golstein and Kroemer, 2007; Vandenabeele et al., 2010). Circumstantial evidence suggesting that necrosis can occur in a regulated fashion has started to accumulate at the end of the twentieth century, when first Laster et al. (1988) and then Vercammen et al. (1998a,b) reported that the engagement of death receptors including tumor necrosis factor receptor 1 (TNFR1) and CD95/FAS can initiate both the apoptotic and the necrotic subroutine of cell death, depending on cell type and the presence of caspase inhibitors (e.g., Z-VAD.fmk). Nevertheless, most doubts on the existence of programmed necrosis have not been cleared until 2005, when Degterev et al. $(2005,2008)$ have reported the discovery of necrostatin 1, a small molecule that exerts potent anti-necrotic effects in vitro and in vivo by targeting the TNFR1-associated kinase receptor interacting protein kinase 1 (RIPK1, also known as RIP1). In this context, Degterev et al. (2005) introduced the term "necroptosis" to indicate the regulated form of necrosis that is induced by TNFR1 ligation. The discovery of necrostatin 1 has quickly been followed by the characterization of other necrostatins (Wang et al., 2007; Degterev et al., 2008), which altogether have ignited two novel and very intense fields of necrosis-related research. First, necrostatins have provided investigators with a convenient tool for disentangling the molecular network that underlies necroptosis, leading in a few years to the characterization of several factors that are required for the initiation and execution of TNFR1-induced programmed necrosis, including the tumor suppressor cylindromatosis (CYLD; Hitomi et al., 2008) and the RIP1-related kinase RIP3 (Cho et al., 2009; He et al., 2009; Zhang et al., 2009). Second, necrostatins have allowed for the demonstration 
that necroptosis is a physiologically and pathologically relevant cell death subroutine, which can be modulated with therapeutic aims. In a few years, it has indeed been shown that the necrostatin-mediated inhibition of RIP1 in vivo exerts cytoprotective effects against neurodegeneration (Yuan et al., 2003), adult brain ischemia (Degterev et al., 2005; Xu et al., 2010), neonatal hypoxia-ischemia (Northington et al., 2011), traumatic brain injury (You et al., 2008), photoreceptor loss-associated retinal disorders (Trichonas et al., 2011), and myocardial infarction (Lim et al., 2007).

The area of necroptosis research is still in its infancy, implying that there is a great number of hitherto unresolved questions, in particular with respect to the molecular mechanisms that ignite, regulate, and execute this cell death subroutine. In this context, it will particularly interesting to elucidate the signaling cascades that are activated in response to different necrotic triggers and to understand whether there is a core machinery for the execution of regulated necrosis, which has already been shown to occur, at least in some instances, also in the absence of RIP1 (Zhang et al., 2009; Upton et al., 2010). A last, but not least, challenge for the upcoming years will be the development of novel cytotoxic chemicals that specifically induces necroptosis, which might turn out to be particularly valuable for cell death induction in apoptosis-refractory cancer cells.

It has been suspected for some time that cancers develop through three successive steps, namely (i) elimination, when immune effector succeed in destroying near-to-all malignant cells; (ii) equilibrium, when the immune system and cancer cells engage in a balanced struggle; and (iii) escape, when transformed cells have succeeded in avoiding immune recognition and hence proliferate in an unrestrained fashion (Smyth et al., 2006; Koebel et al., 2007). Escape can result from the loss of antigenic properties, a process called "immunoevasion," or from active suppression of immune effectors, a process called "immunosubversion" (Zitvogel et al., 2006). There is increasing evidence that restoring the capacity of the immune system to control tumor growth may be of cardinal importance for the efficacy of anticancer therapies. Obeid et al. (2007) demonstrated that cancer cells dying in response to specific pro-apoptotic stimuli including anthracyclins, oxaliplatin, $\gamma$ irradiation, and UVC light are able to elicit an immune response when injected into singenic immunocompetent mice. This response is strong enough to protect mice against subsequent challenges with living cancer cells of the same type (Obeid et al., 2007). In open disagreement with previous, largely accepted theories, the results by Obeid et al. (2007) established the existence of immunogenic apoptosis, thereby opening up an entirely new field of research. Since then, great efforts have been undertaken to identify the molecular determinants of immunogenic cell death, and it has been found that several signaling modules must be activated during cell death for it to elicit a cognate immune response. This complex signaling cascade involves elements of the endoplasmic reticulum stress response (e.g., eukaryotic translation initiation factor 2, $\alpha$-subunit (eIF2 $\alpha$ )-phosphorylating protein kinases), ingredients of the apoptotic machinery, the anterograde transport from the ER to the Golgi apparatus and soluble $N$-ethylmaleimide-sensitive factor (NSF) attachment protein (SNAP) receptor (SNARE)-dependent exocytosis, leading to the co-exposure on the surface of dying cells of the ER chaperones calreticulin (CRT), and protein disulfide isomerase family A, member 3 (PDIA3, also known as ERp57; Obeid et al., 2007; Panaretakis et al., 2008).
By binding to a hitherto uncharacterized receptor on the surface of dendritic cells (DCs), ecto-CRT functions as a potent "eat-me" signal, thus enhancing the uptake of antigens from apoptotic cells and stimulating a DC-driven T cell-mediated immune response (Martins et al., 2010). Several other signals that are required for immunogenic cell death have been decoded during the past few years (Zitvogel et al., 2010), including "find-me" signals that are released by dying cells and stimulate the chemotaxis of immune cells, thereby recruiting them at the site of cell death (e.g., ATP, UTP; Ghiringhelli et al., 2009; Aymeric et al., 2010). Intriguingly, not all "find-me" and "eat-me" signals actively prime immune cells and, in addition, some dying cells expose or release molecules that deliver a "don't find" and/or "don't eat-me" stimulus. Thus, it appears that the immunogenic outcome of cell death is dictated by a complex code of pro- and anti-immunogenic signals that must be interpreted by cells from the immune system including macrophages, DCs, and other antigen-presenting cells (Zitvogel et al., 2010). To date, this molecular and biochemical code has been elucidated only in part. For instance, the DC receptor(s) that bind(s) ecto-CRT remain(s) obscure. Several lines of evidence suggest that the complete eradication of tumors by radio- and chemotherapy requires an active contribution from the immune system. Thus, the induction of immunogenic cell death represents a crucial therapeutic goal. During the upcoming years, molecular and cellular oncologists will have to precisely characterize the signaling cascades that underlie immunogenic cell death. This will drive the development of novel cytotoxic compounds that induce immunogenic cancer cell death and of agents that render immunogenic otherwise nonimmunogenic instances of cancer cell death. The clinical and therapeutic implications of this area of molecular and cellular oncology are huge.

\section{CONCLUSION}

A tendency is emerging to conceive tumors as micro-ecosystems that are composed by a heterogeneous population of cancer (stem) cells as well as a plethora of distinct stromal cells, which either sustain or limit tumor growth at the metabolic, architectonic, trophic, and immunological levels. As discussed above, great advances have been made during the last decade toward a more refined understanding of cancer biology, thus generating unprecedented possibilities for the creation of anticancer agents that are now used in the clinics. For the upcoming years, we, as molecular and cell oncologists, must continue along similar lines to reach an ever more precise characterization of the mechanisms that underlie the origin, survival, and therapeutic response of cancer. Only the future will tell what is the true potential of miRNA-based strategies over CSC-targeted, metabolic, and immunogenic interventions. However, it can be anticipated that our joint efforts will lead to the development of new, efficient approaches for the treatment of this dreadful disease.

\section{ACKNOWLEDGMENTS}

Lorenzo Galluzzi is financed by Apo-Sys. Guido Kroemer is supported by the Ligue Nationale contre le Cancer (Equipes labellisée), Agence Nationale pour la Recherche (ANR), European Commission (Active p53, Apo-Sys, ChemoRes, ApopTrain), Fondation pour la Recherche Médicale (FRM), Institut National du Cancer (INCa), and Cancéropôle Ile-de-France. 


\section{REFERENCES}

Al-Hajj, M., Wicha, M. S., BenitoHernandez, A., Morrison, S. J., and Clarke, M. F. (2003). Prospective identification of tumorigenic breast cancer cells. Proc. Natl. Acad. Sci. U.S.A. 100, 3983-3988.

Aymeric, L., Apetoh, L., Ghiringhelli, F., Tesniere, A., Martins, I., Kroemer, G., Smyth, M. J., and Zitvogel, L. (2010). Tumor cell death and ATP release prime dendritic cells and efficient anticancer immunity. Cancer Res. 70, 855-858.

Bao, S., Wu, Q., McLendon, R. E., Hao, Y., Shi, Q., Hjelmeland, A. B., Dewhirst, M. W., Bigner, D. D., and Rich, J. N. (2006a). Glioma stem cells promote radioresistance by preferential activation of the DNA damage response. Nature 444, 756-760.

Bao, S., Wu, Q., Sathornsumetee, S., Hao, Y., Li, Z., Hjelmeland, A. B., Shi, Q., McLendon, R. E., Bigner, D. D., and Rich, J. N. (2006b). Stem cell-like glioma cells promote tumor angiogenesis through vascular endothelial growth factor. Cancer Res. 66, 7843-7848.

Barabe, F., Kennedy, J. A., Hope, K. J., and Dick, J. E. (2007). Modeling the initiation and progression of human acute leukemia in mice. Science 316 , 600-604.

Beckers, A., Organe, S., Timmermans, L., Scheys, K., Peeters, A., Brusselmans, K., Verhoeven, G., and Swinnen, J. V. (2007). Chemical inhibition of acetylCoA carboxylase induces growth arrest and cytotoxicity selectively in cancer cells. Cancer Res. 67, 8180-8187.

Bonnet, S., Archer, S. L., AllalunisTurner, J., Haromy, A., Beaulieu, C., Thompson, R., Lee, C. T., Lopaschuk, G. D., Puttagunta, L., Harry, G., Hashimoto, K., Porter, C. J., Andrade, M. A., Thebaud, B., and Michelakis, E. D. (2007). A mitochondria-K+ channel axis is suppressed in cancer and its normalization promotes apoptosis and inhibits cancer growth. Cancer Cell 11,37-51.

Brizel, D. M., and Esclamado, R. (2006). Concurrent chemoradiotherapy for locally advanced, nonmetastatic, squamous carcinoma of the head and neck: consensus, controversy, and conundrum. J. Clin. Oncol. 24, 2612-2617.

Calabrese, C., Poppleton, H., Kocak, M., Hogg, T. L., Fuller, C., Hamner, B., Oh, E. Y., Gaber, M. W., Finklestein, D., Allen, M., Frank, A., Bayazitov, I. T., Zakharenko, S. S., Gajjar, A., Davidoff, A., and Gilbertson, R. J. (2007). A perivascular niche for brain tumor stem cells. Cancer Cell 11, 69-82.

Calin, G. A., Dumitru, C. D., Shimizu, M., Bichi, R., Zupo, S., Noch, E., Aldler, H., Rattan, S., Keating,
M., Rai, K., Rassenti, L., Kipps, T., Negrini, M., Bullrich, F., and Croce, C. M. (2002). Frequent deletions and down-regulation of micro- RNA genes miR15 and miR16 at 13q14 in chronic lymphocytic leukemia. Proc. Natl. Acad. Sci. U.S.A. 99, 15524-15529.

Chin, L., Tam, A., Pomerantz, J., Wong, M., Holash, J., Bardeesy, N., Shen, Q., O’Hagan, R., Pantginis, J., Zhou, H., Horner, J. W. II, Cordon-Cardo, C., Yancopoulos, G. D., and DePinho, R. A. (1999). Essential role for oncogenic Ras in tumour maintenance. Nature 400, 468-472.

Cho, Y. S., Challa, S., Moquin, D., Genga, R., Ray, T.D., Guildford, M., and Chan, F. K. (2009). Phosphorylation-driven assembly of the RIP1-RIP3 complex regulates programmed necrosis and virus-induced inflammation. Cell 137, 1112-1123.

Cimmino, A., Calin, G. A., Fabbri, M., Iorio, M. V., Ferracin, M., Shimizu, M., Wojcik, S. E., Aqeilan, R. I., Zupo, S., Dono, M., Rassenti, L., Alder, H., Volinia, S., Liu, C. G., Kipps, T. J., Negrini, M., and Croce, C. M. (2005). miR-15 and miR-16 induce apoptosis by targeting BCL2. Proc. Natl. Acad. Sci. U.S.A. 102, 13944-13949.

Croce, C. M. (2009). Causes and consequences of microRNA dysregulation in cancer. Nat. Rev. Genet. 10, 704-714.

Degterev, A., Hitomi, J., Germscheid, M., Ch'en, I. L., Korkina, O., Teng, X., Abbott, D., Cuny, G. D., Yuan, C., Wagner, G., Hedrick, S. M., Gerber, S. A., Lugovskoy, A., and Yuan, J. (2008). Identification of RIP1 kinase as a specific cellular target of necrostatins. Nat. Chem. Biol. 4, 313-321.

Degterev, A., Huang, Z., Boyce, M., Li, Y., Jagtap, P., Mizushima, N., Cuny, G. D., Mitchison, T.J., Moskowitz,M.A., and Yuan, J. (2005). Chemical inhibitor of nonapoptotic cell death with therapeutic potential for ischemic brain injury. Nat. Chem. Biol. 1, 112-119.

Felsher, D. W., and Bishop, J. M. (1999). Reversible tumorigenesis by MYC in hematopoietic lineages. Mol. Cell 4, 199-207.

Galluzzi, L., Maiuri, M. C., Vitale, I., Zischka, H., Castedo, M., Zitvogel, L., and Kroemer, G. (2007). Cell death modalities: classification and pathophysiological implications. Cell Death Differ. 14, 1237-1243.

Garzon, R., Liu, S., Fabbri, M., Liu, Z., Heaphy, C. E., Callegari, E., Schwind, S., Pang, J., Yu, J., Muthusamy, N., Havelange, V., Volinia, S., Blum, W., Rush, L. J., Perrotti, D., Andreeff, M., Bloomfield, C. D., Byrd, J. C., Chan, K., Wu, L. C., Croce, C. M., and Marcucci, G. (2009). MicroRNA-29b induces global DNA hypomethylation and tumor suppressor gene reexpression in acute myeloid leukemia by targeting directly DNMT3A and 3B and indirectly DNMT1. Blood 113, 6411-6418. Ghiringhelli, F., Apetoh, L., Tesniere, A., Aymeric, L., Ma, Y., Ortiz, C., Vermaelen, K., Panaretakis, T., Mignot, G., Ullrich, E., Perfettini, J. L., Schlemmer, F., Tasdemir, E., Uhl, M., Génin, P., Civas, A., Ryffel, B. Kanellopoulos, J., Tschopp, J., André, F., Lidereau, R., McLaughlin, N. M., Haynes, N. M., Smyth, M. J., Kroemer, G., and Zitvogel, L. (2009). Activation of the NLRP3 inflammasome in dendritic cells induces IL-1betadependent adaptive immunity against tumors. Nat. Med. 15, 1170-1178.

Golstein, P., and Kroemer, G. (2007). Cell death by necrosis: towards a molecular definition. Trends Biochem. Sci. 32, 37-43.

Gottlieb, E., and Tomlinson, I. P. (2005). Mitochondrial tumour suppressors: a genetic and biochemical update. Nat Rev. Cancer 5, 857-866.

Greenman, C., Stephens, P., Smith, R. Dalgliesh, G. L., Hunter, C., Bignell, G., Davies, H., Teague, J., Butler, A., Stevens, C., Edkins, S., O’Meara, S., Vastrik, I., Schmidt, E. E., Avis, T. Barthorpe, S., Bhamra, G., Buck, G., Choudhury, B., Clements, J., Cole, J., Dicks, E., Forbes, S., Gray, K., Halliday, K., Harrison, R., Hills, K., Hinton, J. Jenkinson, A., Jones, D., Menzies, A., Mironenko, T., Perry, J., Raine, K. Richardson, D., Shepherd, R., Small,A., Tofts, C., Varian, J., Webb, T., West, S., Widaa, S., Yates, A., Cahill, D. P., Louis, D. N., Goldstraw, P., Nicholson, A. G., Brasseur, F., Looijenga, L., Weber, B. L., Chiew, Y. E., DeFazio, A., Greaves, M F., Green, A. R., Campbell, P., Birney, E., Easton, D. F., Chenevix-Trench, G., Tan, M. H., Khoo, S. K., Teh, B. T., Yuen, S. T., Leung, S. Y., Wooster R., Futreal, P. A., and Stratton, M. R. (2007). Patterns of somatic mutation in human cancer genomes. Nature 446, 153-158.

Guzman, M. L., Rossi, R. M., Karnischky, L., Li, X., Peterson, D. R., Howard, D. S. and Jordan, C. T. (2005). The sesquiterpene lactone parthenolide induces apoptosis of human acute myelogenous leukemia stem and progenitor cells. Blood 105, 4163-4169.

Hahn, W. C., and Weinberg, R. A. (2002) Modelling the molecular circuitry of cancer. Nat. Rev. Cancer 2, 331-341.

Hanahan, D., and Weinberg, R. A. (2000). The hallmarks of cancer. Cell 100, 57-70.

Hatzivassiliou, G., Zhao, F., Bauer, D. E., Andreadis, C., Shaw, A. N., Dhanak, D. Hingorani, S. R., Tuveson, D. A., and Thompson, C. B. (2005). ATP citrate lyase inhibition can suppress tumor cell growth. Cancer Cell 8, 311-321.

He, S., Wang, L., Miao, L., Wang, T., Du, F., Zhao, L., and Wang, X. (2009). Receptor interacting protein kinase-3 determines cellular necrotic response to TNF-alpha. Cell 137, 1100-1111.

Heppner, G. H., and Miller, B. E. (1983). Tumor heterogeneity: biological implications and therapeutic consequences. Cancer Metastasis Rev. 2, 5-23.

Hewitt, H. B. (1958). Studies of the dissemination and quantitative transplantation of a lymphocytic leukaemia of CBA mice. Br. J. Cancer 12, 378-401.

Hitomi, J., Christofferson, D. E., Ng, A., Yao, J., Degterev, A., Xavier, R. J., and Yuan, J. (2008). Identification of a molecular signaling network that regulates a cellular necrotic cell death pathway. Cell 135, 1311-1323.

Huettner, C. S., Zhang, P., Van Etten, R.A., and Tenen, D. G. (2000). Reversibility of acute B-cell leukaemia induced by BCR-ABL1. Nat. Genet. 24, 57-60.

Ishikawa, F., Yoshida, S., Saito, Y., Hijikata, A., Kitamura, H., Tanaka, S., Nakamura, R., Tanaka, T., Tomiyama, H., Saito, N., Fukata, M., Miyamoto, T., Lyons, B., Ohshima, K., Uchida, N., Taniguchi, S., Ohara, O., Akashi, K., Harada, M., and Shultz, L. D. (2007). Chemotherapy-resistant human AML stem cells home to and engraft within the bone-marrow endosteal region. Nat. Biotechnol. 25, 1315-1321.

Jain, M., Arvanitis, C., Chu, K., Dewey, W., Leonhardt, E., Trinh, M., Sundberg, C. D., Bishop, J. M., and Felsher, D. W. (2002). Sustained loss of a neoplastic phenotype by brief inactivation of MYC. Science 297, 102-104.

Jin, L., Hope, K. J., Zhai, Q., Smadja-Joffe, F., and Dick, J. E. (2006). Targeting of CD44 eradicates human acute myeloid leukemic stem cells. Nat. Med. 12, 1167-1174.

Johnson, S. M., Grosshans, H., Shingara, J., Byrom, M., Jarvis, R., Cheng, A., Labourier, E., Reinert, K. L., Brown, D., and Slack, F. J. (2005). RAS is regulated by the let-7 microRNA family. Cell 120, 635-647.

Koebel, C. M., Vermi, W., Swann, J. B., Zerafa, N., Rodig, S. J., Old, L. J., Smyth, M. J., and Schreiber, R. D. (2007).Adaptive immunity maintains occult cancer in an equilibrium state. Nature 450, 903-907.

Kota, J., Chivukula, R. R., O’Donnell, K. A., Wentzel, E. A., Montgomery, C. L., Hwang, H. W., Chang, T. C., Vivekanandan, P., Torbenson, M., Clark, K. R., Mendell, J. R., and Mendell, J. T. (2009). Therapeutic microRNA delivery suppresses 
tumorigenesis in a murine liver cancer model. Cell 137, 1005-1017.

Kroemer, G., Galluzzi, L., and Brenner, C. (2007). Mitochondrial membrane permeabilization in cell death. Physiol. Rev. 87, 99-163.

Kroemer, G., Galluzzi, L., Vandenabeele,P., Abrams, J., Alnemri, E. S., Baehrecke, E. H., Blagosklonny, M. V., El-Deiry, W. S., Golstein, P., Green, D. R., Hengartner, M., Knight, R. A., Kumar, S., Lipton, S. A., Malorni, W., Nuñez, G., Peter, M. E, Tschopp, J., Yuan, J., Piacentini,M.,Zhivotovsky, B., Melino, G.; Nomenclature Committee on Cell Death 2009. (2009). Classification of cell death: recommendations of the Nomenclature Committee on Cell Death 2009. Cell Death Differ. 16,3-11.

Kroemer, G., and Pouyssegur, J. (2008). Tumor cell metabolism: cancer's Achilles' heel. Cancer Cell 13, 472-482.

Lapidot, T., Sirard, C., Vormoor, J., Murdoch, B., Hoang, T., CaceresCortes, J., Minden, M., Paterson, B., Caligiuri, M.A., and Dick, J. E. (1994). A cell initiating human acute myeloid leukaemia after transplantation into SCID mice. Nature 367, 645-648.

Laster, S. M., Wood, J. G., and Gooding, L. R. (1988). Tumor necrosis factor can induce both apoptic and necrotic forms of cell lysis. J. Immunol. 141, 2629-2634.

Lee, J. Y., Nakada, D., Yilmaz, O. H., Tothova, Z., Joseph, N. M., Lim, M. S., Gilliland, D. G., and Morrison, S. J. (2010). mTOR activation induces tumor suppressors that inhibit leukemogenesis and deplete hematopoietic stem cells after Pten deletion. Cell Stem Cell 7, 593-605.

Lim, S. Y., Davidson, S. M., Mocanu, M. M., Yellon, D. M., and Smith, C. C. (2007). The cardioprotective effect of necrostatin requires the cyclophilin-D component of the mitochondrial permeability transition pore. Cardiovasc. Drugs Ther. 21, 467-469.

Luo, J., Solimini, N. L., and Elledge, S. J. (2009). Principles of cancer therapy: oncogene and non-oncogene addiction. Cell 136, 823-837.

MacKenzie, E. D., Selak, M.A., Tennant, D. A., Payne, L. J., Crosby, S., Frederiksen, C. M., Watson, D. G., and Gottlieb, E. (2007). Cell-permeating alphaketoglutarate derivatives alleviate pseudohypoxia in succinate dehydrogenase-deficient cells. Mol. Cell. Biol. 27, 3282-3289.

Martins, I., Kepp, O., Galluzzi, L., Senovilla, L., Schlemmer, F., Adjemian, S., Menger, L., Michaud, M., Zitvogel, L., and Kroemer, G. (2010). Surfaceexposed calreticulin in the interaction between dying cells and phagocytes. Ann. N. Y. Acad. Sci. 1209, 77-82.
Mendell, J. T. (2008). miRiad roles for the miR-17-92 cluster in development and disease. Cell 133, 217-222.

Meng, F., Henson, R., Wehbe-Janek, H., Ghoshal, K., Jacob, S. T., and Patel, T. (2007). MicroRNA-21 regulates expression of the PTEN tumor suppressor gene in human hepatocellular cancer. Gastroenterology 133, 647-658.

Morselli, E., Galluzzi, L., Kepp, O., Vicencio, J. M., Criollo, A., Maiuri, M. C., and Kroemer, G. (2009). Anti- and pro-tumor functions of autophagy. Biochim. Biophys. Acta 1793, 1524-1532.

Northington, F. J., Chavez-Valdez, R., Graham, E. M., Razdan, S., Gauda, E. B., and Martin, L. J. (2011). Necrostatin decreases oxidative damage, inflammation, and injury after neonatal HI. J. Cereb. Blood Flow Metab. 31, 178-189.

Nowell, P.C. (1976). The clonal evolution of tumor cell populations. Science 194, 23-28.

Obeid, M., Tesniere, A., Ghiringhelli, F., Fimia, G. M., Apetoh, L., Perfettini, J. L., Castedo, M., Mignot, G., Panaretakis, T., Casares, N., Métivier, D., Larochette, N., van Endert, P., Ciccosanti, F., Piacentini, M., Zitvogel, L., and Kroemer, G. (2007). Calreticulin exposure dictates the immunogenicity of cancer cell death. Nat. Med. 13, 54-61.

O’Donnell, K. A., Wentzel, E. A., Zeller, K. I., Dang, C. V., and Mendell, J. T. (2005). c-Myc-regulated microRNAs modulate E2F1 expression. Nature 435, 839-843.

Panaretakis, T., Joza, N., Modjtahedi, N., Tesniere, A., Vitale, I., Durchschlag, M., Fimia, G. M., Kepp, O., Piacentini, M., Froehlich, K. U., van Endert, P., Zitvogel, L., Madeo, F., and Kroemer, G. (2008). The co-translocation of ERp57 and calreticulin determines the immunogenicity of cell death. Cell Death Differ. 15, 1499-1509.

Pelengaris, S., Littlewood, T., Khan, M., Elia, G., and Evan, G. (1999). Reversible activation of c-Myc in skin: induction of a complex neoplastic phenotype by a single oncogenic lesion. Mol. Cell 3, 565-577.

Piccirillo, S. G., Reynolds, B. A., Zanetti, N., Lamorte, G., Binda, E., Broggi, G., Brem, H., Olivi, A., Dimeco, F., and Vescovi,A. L. (2006). Bone morphogenetic proteins inhibit the tumorigenic potential of human brain tumourinitiating cells. Nature 444, 761-765.

Pollard, P. J., Briere, J. J., Alam, N. A., Barwell, J., Barclay, E., Wortham, N. C., Hunt, T., Mitchell, M., Olpin, S., Moat, S. J., Hargreaves, I. P., Heales, S. J., Chung, Y. L., Griffiths, J. R., Dalgleish, A., McGrath, J.A., Gleeson, M. J., Hodgson, S. V., Poulsom,
R., Rustin, P, and Tomlinson, I. P. (2005). Accumulation of Krebs cycle intermediates and over-expression of HIFlalpha in tumours which result from germline $\mathrm{FH}$ and $\mathrm{SDH}$ mutations. Hum. Mol. Genet. 14 2231-2239.

Pouyssegur, J., Dayan, F., and Mazure, N. M. (2006). Hypoxia signalling in cancer and approaches to enforce tumour regression. Nature 441, 437-443.

Reya, T., Morrison, S. J., Clarke, M. F., and Weissman, I. L. (2001). Stem cells, cancer, and cancer stem cells. Nature 414 105-111.

Ryan, B. M., Robles, A. I., and Harris, C. C. (2010). Genetic variation in microRNA networks: the implications for cancer research. Nat. Rev. Cancer 10, 389-402.

Saito, Y., Liang, G., Egger, G., Friedman, J. M., Chuang, J. C., Coetzee, G. A., and Jones, P. A. (2006). Specific activation of microRNA-127 with downregulation of the proto-oncogene BCL6 by chromatin-modifying drugs in human cancer cells. Cancer Cell 9, 435-443.

Selak, M. A., Armour, S. M., MacKenzie, E. D., Boulahbel, H., Watson, D. G., Mansfield, K. D., Pan, Y., Simon, M. C., Thompson, C. B., and Gottlieb, E. (2005). Succinate links TCA cycle dysfunction to oncogenesis by inhibiting HIF-alpha prolyl hydroxylase. Cancer Cell 7, 77-85.

Shirasawa, S., Furuse, M., Yokoyama, N., and Sasazuki, T. (1993). Altered growth of human colon cancer cell lines disrupted at activated Ki-ras. Science 260, 85-88.

Simons, A. L., Fath, M. A., Mattson, D. M., Smith, B. J., Walsh, S. A., Graham, M. M., Hichwa, R. D., Buatti, J. M. Dornfeld, K., and Spitz, D. R. (2007). Enhanced response of human head and neck cancer xenograft tumors to cisplatin combined with 2-deoxy$\mathrm{D}$-glucose correlates with increased 18F-FDG uptake as determined by PET imaging. Int. J. Radiat. Oncol. Biol. Phys. 69, 1222-1230.

Smyth, M. J., Dunn, G. P., and Schreiber, R. D. (2006). Cancer immunosurveillance and immunoediting: the roles of immunity in suppressing tumor development and shaping tumor immunogenicity. Adv. Immunol. 90, 1-50.

Solimini, N. L., Luo, J., and Elledge, S. J. (2007). Non-oncogene addiction and the stress phenotype of cancer cells. Cell 130, 986-988.

Trichonas, G., Murakami, Y., Thanos, A. Morizane, Y., Kayama, M., Debouck, C. M., Hisatomi, T., Miller, J. W. and Vavvas, D. G. (2011). Receptor interacting protein kinases mediate retinal detachment-induced photoreceptor necrosis and compensate for inhibition of apoptosis. Proc. Natl. Acad. Sci. U.S.A. doi: 10.1073/ pnas.1009179107

Upton, J. W., Kaiser, W. J., and Mocarski, E. S. (2010). Virus inhibition of RIP3dependent necrosis. Cell Host Microbe 7, 302-313.

Vandenabeele, P., Galluzzi, L., Vanden Berghe, T., and Kroemer, G. (2010). Molecular mechanisms of necroptosis: an ordered cellular explosion. Nat. Rev. Mol. Cell Biol. 11, 700-714.

Ventura, A., Kirsch, D. G., McLaughlin, M. E., Tuveson, D. A., Grimm, J., Lintault, L., Newman, J., Reczek, E.E., Weissleder, R., and Jacks, T. (2007). Restoration of p53 function leads to tumour regression in vivo. Nature 445, 661-665.

Vercammen, D., Beyaert, R., Denecker, G., Goossens, V., Van Loo, G., Declercq, W., Grooten, J., Fiers, W., and Vandenabeele, P. (1998a). Inhibition of caspases increases the sensitivity of L929 cells to necrosis mediated by tumor necrosis factor. J. Exp. Med. 187, 1477-1485.

Vercammen, D., Brouckaert, G., Denecker, G., Van de Craen, M., Declercq, W., Fiers, W., and Vandenabeele, P. (1998b). Dual signaling of the Fas receptor: initiation of both apoptotic and necrotic cell death pathways. $J$. Exp. Med. 188, 919-930.

Visvader, J.E., and Lindeman, G. J. (2008). Cancer stem cells in solid tumours: accumulating evidence and unresolved questions. Nat. Rev. Cancer 8 , 755-768.

Wang, K., Li, J., Degterev, A., Hsu, E., Yuan, J., and Yuan, C. (2007) Structure-activity relationship analysis of a novel necroptosis inhibitor, Necrostatin-5. Bioorg. Med. Chem. Lett. 17, 1455-1465.

Xu, X., Chua, K. W., Chua, C. C., Liu, C. F., Hamdy, R. C., and Chua, B. H. (2010). Synergistic protective effects of humanin and necrostatin-1 on hypoxia and ischemia/reperfusion injury. Brain Res. 1355, 189-194.

Xue, W., Zender, L., Miething, C., Dickins, R. A., Hernando, E., Krizhanovsky, V., Cordon-Cardo, C., and Lowe, S. W. (2007). Senescence and tumour clearance is triggered by $\mathrm{p} 53$ restoration in murine liver carcinomas. Nature 445 , 656-660.

Yilmaz, O. H., Valdez, R., Theisen, B. K., Guo, W., Ferguson, D. O., Wu, H., and Morrison, S. J. (2006). Pten dependence distinguishes haematopoietic stem cells from leukaemia-initiating cells. Nature 441, 475-482.

You, Z., Savitz, S. I., Yang, J., Degterev, A., Yuan, J., Cuny, G. D., Moskowitz, M. A., and Whalen, M. J. (2008). Necrostatin-1 reduces histopathology 
and improves functional outcome after controlled cortical impact in mice. J. Cereb. Blood Flow Metab. 28, 1564-1573.

Yuan, J., Lipinski, M., and Degterev, A. (2003). Diversity in the mechanisms of neuronal cell death. Neuron 40 , 401-413.

Zhang, D. W., Shao, J., Lin, J., Zhang, N., Lu, B. J., Lin, S. C., Dong, M. Q., and Han, J. (2009). RIP3, an energy metabolism regulator that switches TNF-induced cell death from apoptosis to necrosis. Science 325, 332-336.

Zitvogel, L., Kepp, O., and Kroemer, G. (2010). Decoding cell death signals in inflammation and immunity. Cell 140, 798-804.

Zitvogel, L., Tesniere, A., and Kroemer, G. (2006). Cancer despite immunosurveillance: immunoselection and immunosubversion. Nat. Rev. Immunol. 6, 715-727.
Conflict of Interest Statement: The authors declare that the research was conducted in the absence of any commercial or financial relationships that could be construed as a potential conflict of interest.

Received: 01 February 2011; accepted: 11 March 2011; published online: 28 March 2011.

Citation: Galluzzi L, Vitale I and Kroemer $G$ (2011) Past, present, and future of molecular and cellular oncology. Front. Oncol. 1:1. doi: 10.3389/fonc.2011.00001 This article was submitted to Frontiers in Molecular and Cellular Oncology, a specialty of Frontiers in Oncology. Copyright (c) 2011 Galluzzi, Vitale and Kroemer. This is an open-access article subject to an exclusive license agreement between the authors and Frontiers Media SA, which permits unrestricted use, distribution, and reproduction in any medium, provided the original authors and source are credited. 